\title{
Application of WSN Fire Monitoring System in Coal Mining
}

\author{
https://doi.org/10.3991/ijoe.v13i03.6856 \\ Chengyu Bai \\ Xi'an Railway Vocational \& Technical Institute, Shaanxi, Xi'an, China \\ bcy_2000@163.com
}

\begin{abstract}
Targeted at the potential fire in coal mine production, this paper proposes a coal mine fire monitoring system based on Zig-bee technology, and discusses the network data transmission process in the system. When the system is applied to an actual coal mine, it achieves a sound fire monitoring effect. The wireless sensor network (WSN) coal mine fire monitoring system consists of such three subsystems as data acquisition subsystem, control center subsystem and emergency response subsystem. With sensor nodes as the basic unit, the WSN is divided into five parts: sensor module, treatment module, wireless communication module, location module and power supply module. The system can monitor the air temperature, humidity and smoke concentration of fire in the coal mine, and provide effective basis for monitoring department to make decisions on fire prevention and control measures. The on-site monitoring test shows that, in the event of a fire, the WSN can monitor the trend of fire in the coal mine effectively, reflect the temperature distribution in details, and issue alarms accurately. The conclusion offers a theoretical reference for the development of coal mine fire monitoring technology.
\end{abstract}

Key Words - coal mine fire monitoring system, wireless sensor network, ZigBee, temperature distribution

\section{Introduction}

Underground coal mine production conditions are very poor. What is worse, there are a variety of hazard sources, such as gas, groundwater leakage, initial roof pressure and fire. Among them, the fire caused by spontaneous combustion of coal and gas explosion has become a global disaster, which poses a serious threat to the work safety of the coal mine and the safety of the natural environment, and results in tremendous economic losses [1-4]. Investigations show that the direct economic losses caused by coal mine fires in China exceed USD 300 million each year, and the $\mathrm{CO}_{2}$ generated from the spontaneous combustion of coal in China accounts for 0.1 to 0.2 percent of global fossil fuel carbon emissions [5].

Previous research has shown that the spontaneous combustion of coal in recent years has the following characteristics: due to mine exploitation, the coalfield fire develops to the deep in a more subtle way, and becomes increasingly difficult to con- 
trol [6-7]. Much research has been done on the mechanism, monitoring and prediction of spontaneous combustion of coal [8-11]. The monitoring of mine fires is undoubtedly the most important aspect in the above studies. Traditionally, underground fire monitoring mostly uses linear temperature monitoring. Providing very little information and few functions, the traditional monitoring method is only capable of issuing alarm signals in an approximate region when a fire occurs. The other type of fire monitor is the electrical temperature sensor. Susceptible to strong electromagnetic interference, it is not suitable for operation in flammable, explosive or corrosive environment. Thanks to the continuous maturing of FBG sensing technology at the beginning of the 21st century, coal mine fire monitoring used to rely heavily on grating sensing technology [12]. The optical fiber temperature measurement technology was extensively promoted to detect and monitor of the heat trend and local temperature caused by various underground activities in the coal mine [13]. However, the new technology has some insurmountable flaws. The large-scale wiring takes up limited pipeline resources, the overall fire monitoring goes out of control at the failure of some of the monitoring points, the pre-planned and designed monitoring points cannot be changed or expanded according to the actual development, and the system cannot be upgraded because the sensors are fixed. Recent years has seen the rapid development of a new wireless network technology, the wireless sensor network (WSN). It realizes the seamless connection between people and the monitoring area through sensor nodes scattered in the monitoring area and real-time monitoring of environmental regions [14]. As a concrete form of WSN, Zig-Bee has the advantages of low rate, low power consumption, low cost, self-organizing network and selfrepairing ability [15]. It has been applied to monitor coal fire and locate spontaneous combustion fire sources on each layer in some coal mines, yielding relevant research results.

Targeted at the potential fire in coal mine production, this paper proposes a coal mine fire monitoring system based on Zig-bee technology, and discusses the network data transmission process in the system. When the system is applied to an actual coal mine, it achieves a sound fire monitoring effect. The conclusion offers a theoretical reference for the development of coal mine fire monitoring technology.

\section{WSN-based coal mine fire monitoring system}

In the coal mine, the coal auto-ignition happens under the following conditions: fire source, environmental factors and underground combustibles. Coal fires are the result of a combination of these factors. In addition, the coal mine air temperature and air humidity are important parameters of fire monitoring. The air temperature directly affects the ignition of combustibles, and the relative humidity of the air affects the evaporation of water in combustibles. The underground smoke concentration signifies the fire propagation. Knowing the concentration helps carry out rescue operations. The other factors are not taken into consideration in this paper. 


\subsection{Coal mine fire monitoring system}

Proposed in recent years, the WSN is a system of intelligent autonomous network composed of multiple tiny sensor nodes. The system combines computer technology, communication technology and sensor network technology, and has a wide application prospect in unattended environment, harsh climate environment and disaster environment. Zig-bee is an emerging wireless communication technology of WSN. It has the advantages of low cost, low rate and low power consumption. It operates in the ISM band of $2.4 \mathrm{GHz}$, provides 128-bit advanced encryption software, and adopts the IEEE802 security element.

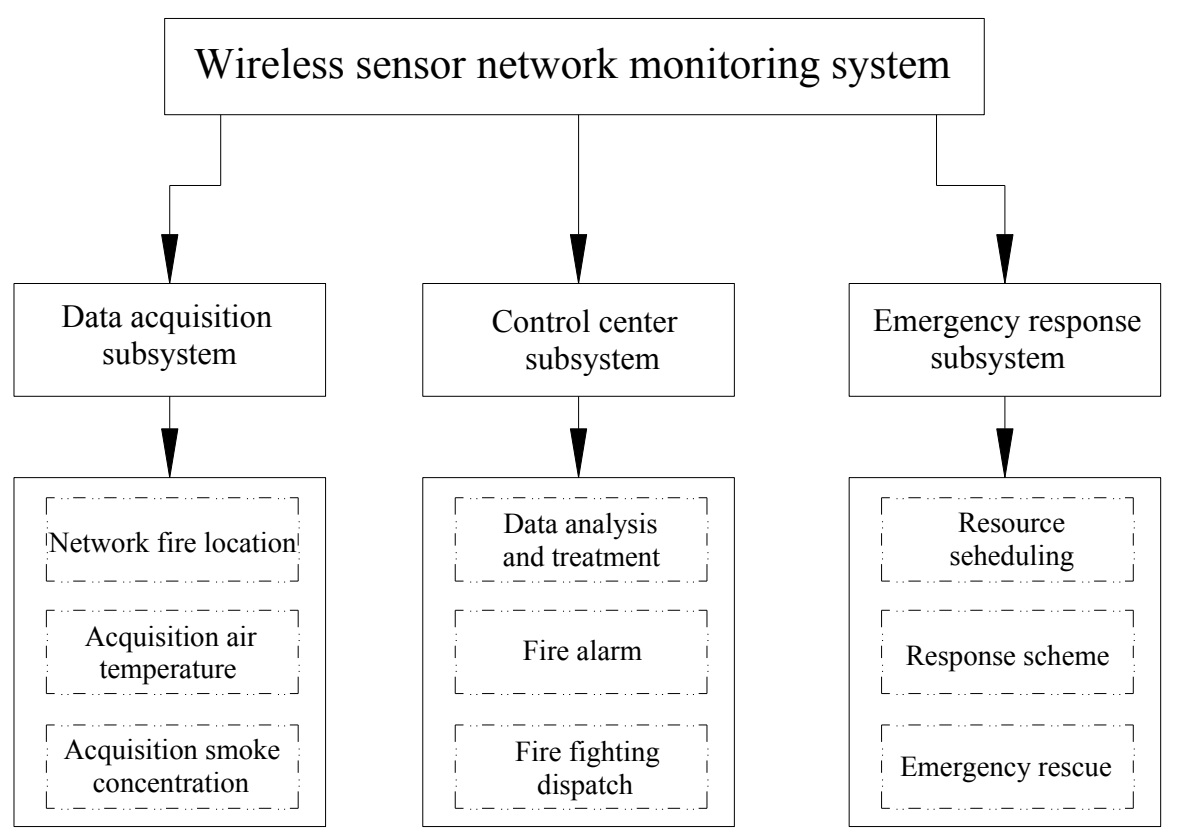

Fig. 1. The mine fire monitoring system and its function structure

This paper sets up a coal mine fire monitoring system based on Zig-bee WSN, as shown in Figure 1. The system is divided into three subsystems, namely, data acquisition subsystem, control center subsystem and emergency response subsystem. The data acquisition subsystem identifies the network fire location, and accesses air temperature and smoke concentration in real time; the control center subsystem summarizes, analyzes and processes the information uploaded by all network nodes, sends fire alarms and carries out firefighting dispatch; the emergency response subsystem mainly schedules emergency resources and prepares reasonable response schemes and the emergency rescue measures.

The basic unit of the WSN is the sensor node. The whole network system is composed of multiple sensor nodes. See Figure 2 for the structure of sensor node. As shown in the figure, the sensor node is divided into five parts: the sensor module, 
treatment module, wireless communication module, location module and power supply module. The sensor module is mainly responsible for collection of air humidity, temperature and smoke concentration in the coal mine and $\mathrm{A} / \mathrm{D}$ conversion. The treatment module is made up of the processor and the memory. It is mainly responsible for the operation and data storage of the sensor node. The wireless communication module is mainly responsible for information exchange and data reception/transmission. The location module identifies the location of fire with the aid of GPS, and broadcast its own location to the other nodes in its surroundings. After receiving the location, the other nodes make relative positioning and eventually transmit the specific location of the fire to the monitoring center. The power supply module is mainly responsible for powering other modules and driving the entire node.

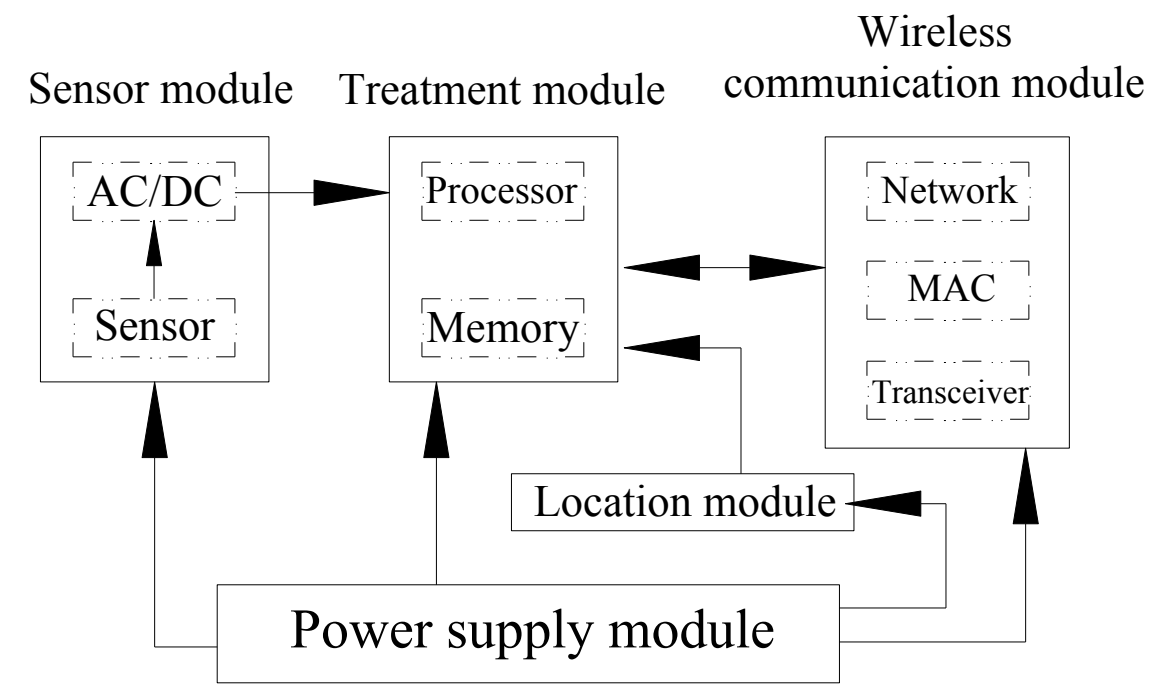

Fig. 2. The composition of sensor node

The core chip of the sensor node is JN5139, which has four working modules, including timer, 12-bit comparator, temperature and humidity sensor and smoke sensor. The chip of the temperature and humidity sensor is SHT10 with digital output, adjustment-free automatic sleep and other functions. The smoke sensor boasts advantages like good stability, fast response, and small size. As for gateway access, JN5139 wireless RFID module is used to provide bi-directional communication between the coordinator node and the sensor node. It not only receives the information from the sensor nodes, but also issues control command to all nodes.

\subsection{Fire data transmission process}

If the coal mine is under fire, the location of the wireless network sensor is identified in the steps shown in Figure 3. The WSN is designed to automatically locate the 
fire, and the monitoring department regularly conducts data updates and repositioning of the network nodes. Hence, there are two ways to acquire the location data of subsystems: the active monitoring of network nodes and the passive response to the command of the monitoring host. The specific procedure of the former goes as follows. After arranging multiple network sensor nodes in the coal mine, the entire monitoring network is set up through the coordinator, and let all sensor nodes choose to join the network. Upon completion, the monitoring system would calculate the location based on the location algorithm sent by the anchor node and upload the information to the remote monitoring host. The monitoring host then feeds the information back to the nodes around the anchor node. If the number of location information is fewer than the number of parameters required by the location algorithm, the surrounding nodes would go through secondary positioning based on the location calculation. If the secondary positioning also fails, the positioning information is transmitted back to the remote monitoring host, and the host would request the anchor node to reposition until the positioning is correct.

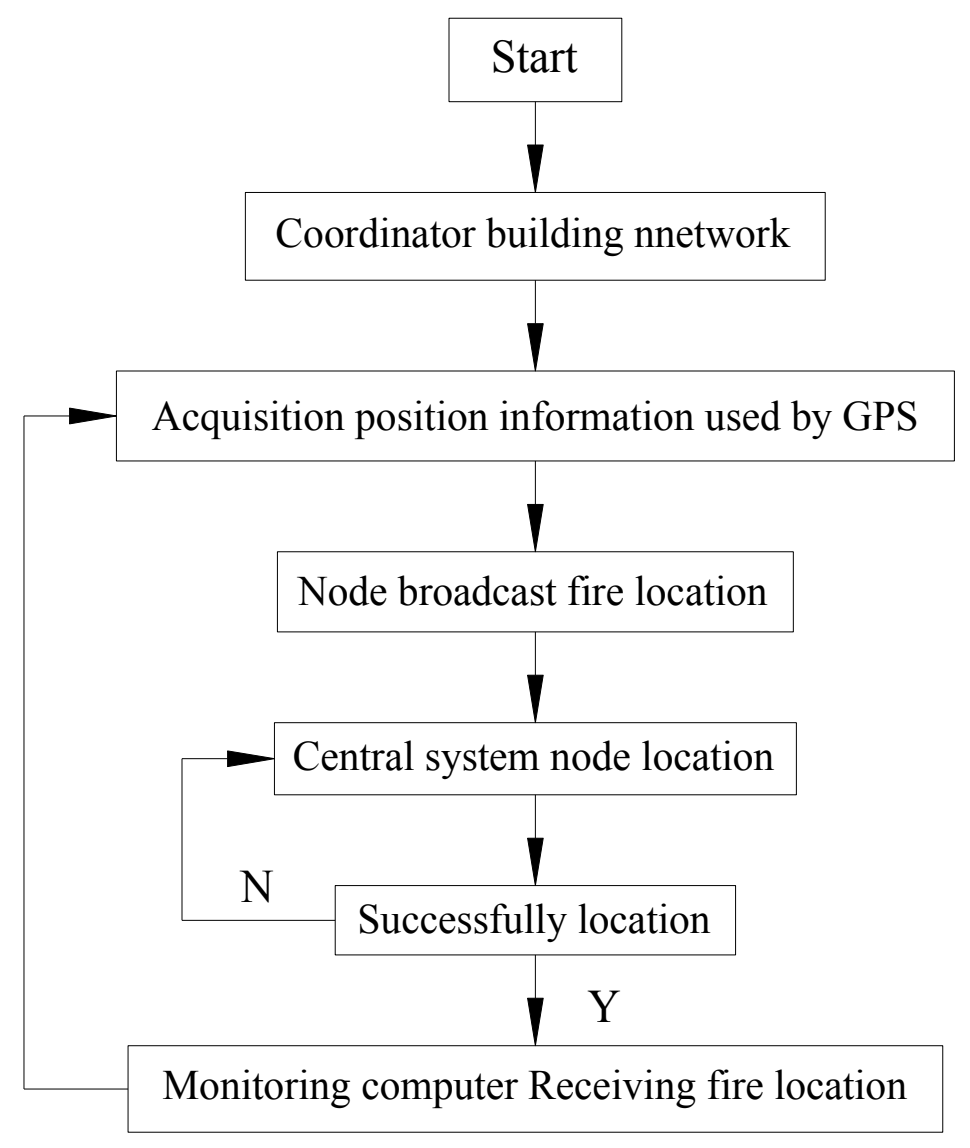

Fig. 3. The system networking and location 
The fire data transmission process is displayed in Figure 4. In order to manage data and monitor air temperature and humidity, and the spread of smoke in real time, the monitoring department remotely controls and operates the fire prevention and control server in the coal mine. The above $d$ is transmitted to the gateway node through the wireless network, and the gateway node searches the routing list according to the received command and pairs the command with a target coordinator. Then, the target coordinator broadcasts relevant data and wake up the cluster head of the wireless transmission network, which fuses the data and activates other dormant nodes. The data is eventually transmitted through the network to the monitoring host. If packet loss occurs during the wake-up process or the communication with the target coordinator fails, the cluster head would generate an error report and sends it to the monitoring host for filing.

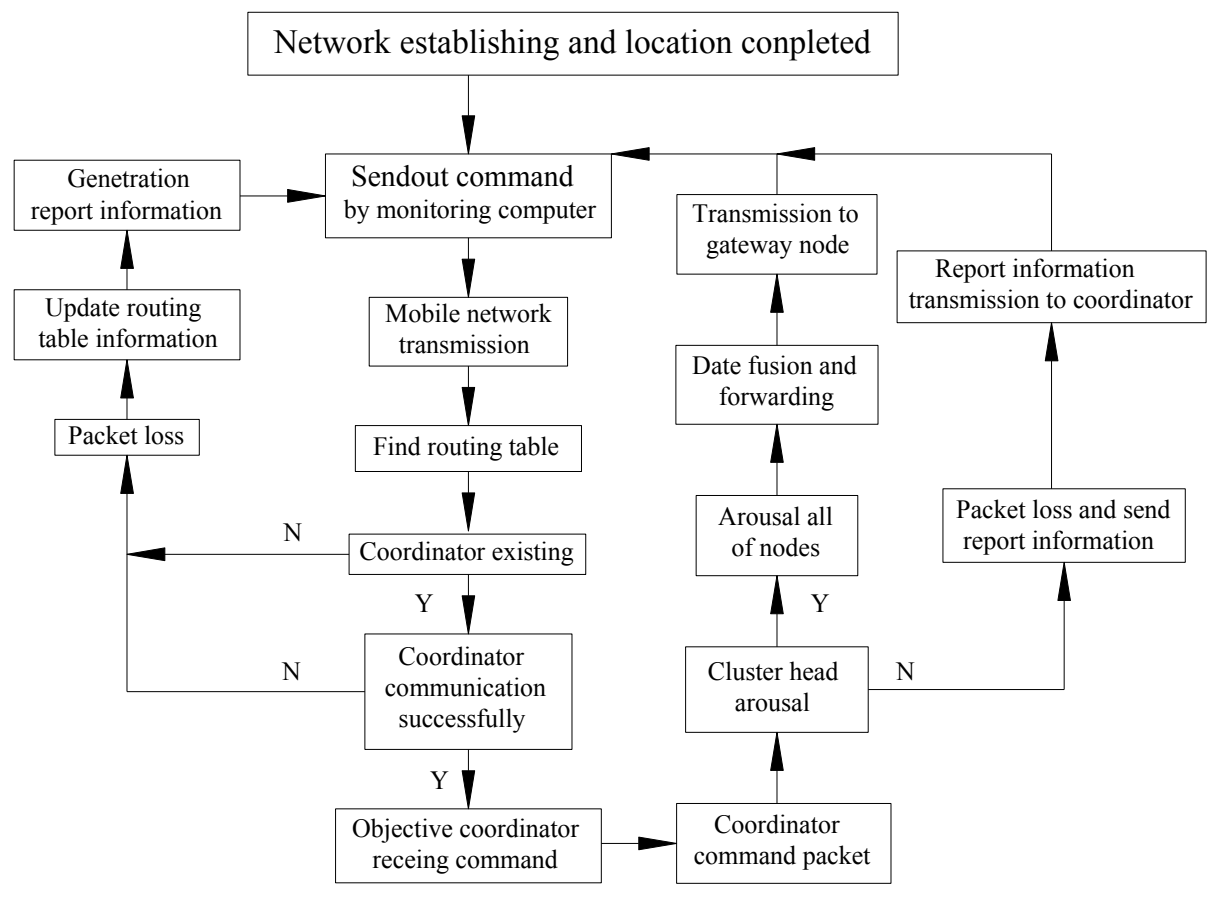

Fig. 4. The process of data transmission

\section{Experimental research of coal mine fire monitoring}

In order to verify the validity and accuracy of the proposed model, the author arranges several WSN nodes in an actual mine, and selects four areas in the roadway as the test areas for fire monitoring, each of which is $100 \mathrm{~m}$ long. The distance between neighboring WSN nodes are $10 \mathrm{~m}$. One node is chosen in each area. Area 1 and Area 2 reflect the actual environment of the mine, while Area 3 and Area 4 simulate a coal mine fire. In Area 3, the author selects the sensor node at the original of fire; in Area 
4, author selects the sensor node $20 \mathrm{~m}$ away from the origin of fire. See Figure 5 for the data on temperature over $300 \mathrm{~min}$ recorded at the said 4 nodes. Each data point represents the average temperature within $10 \mathrm{~min}$.

The fire alarm temperature of each node in the system is set to $55^{\circ} \mathrm{C}$. It can be seen from the figure that the temperatures of the wireless network sensors in Area 1 and Area 2 are normal, which are respectively $17^{\circ} \mathrm{C}$ and $20^{\circ} \mathrm{C}$ on average. In Area 3 and Area 4 , the coal is ignited artificially at $70 \mathrm{~min}$ and $80 \mathrm{~min}$ respectively. As shown in Figure 5(b), within a very short time after the fire broke out, the monitored temperature of the sensor node in Area 3 rises rapidly and triggers the alarm system. After the fire is put out, the ambient temperature continues to rise to the peak of $86^{\circ} \mathrm{C}$. Then, the temperature begins to decline, and drops to the pre-fire level of $20^{\circ} \mathrm{C}$ at $160 \mathrm{~min}$. The whole process takes $90 \mathrm{~min}$. The temperature change of the sensor in Area 4 is almost the same as that in Area 3. Because the sensor is 20 meters away from the fire, the ambient temperature of Sensor 4 increases at a relatively slower pace and the peak temperature is only $61^{\circ} \mathrm{C}$. The above analysis proves that the proposed WSN is capable of monitoring the fire in the coal mine effectively.

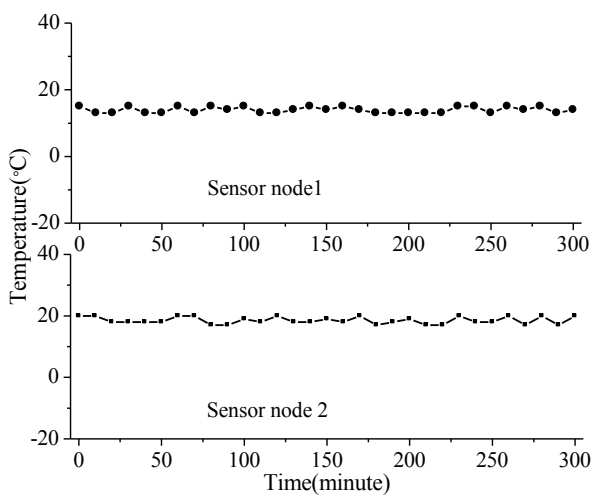

(a) Sensor nodes 1 and 2

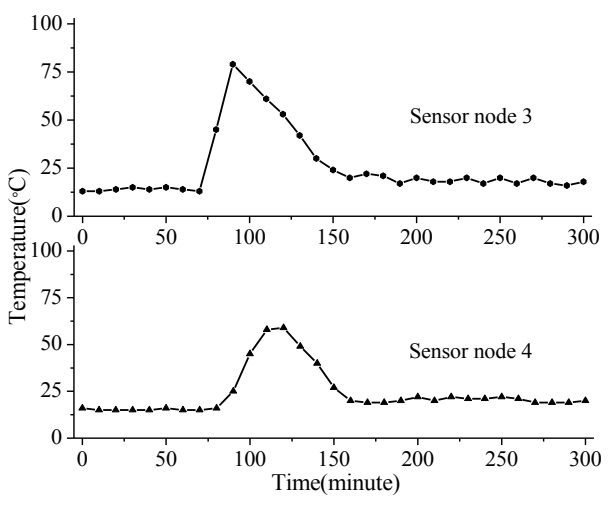

(b) Sensor nodes 3 and 4

Fig. 5. The temperature variation of 4 sensor nodes in 300 minutes

Figure 6 illustrates the temperature variations of the wireless network sensors within 100 meters in the test area under a simulated coal mine fire at 5s, 20s, 40s and 60s. For ease of recording, the center of the test area is chosen as the ignition point of the artificial fire. Figure 7 displays the temperature variations of all wireless network sensors $5 \mathrm{~s}, 20 \mathrm{~s}, 40$, and $60 \mathrm{~s}$ after the fire is extinguished.

As shown in Figure 6, the temperatures at the monitoring points have little changes at $5 \mathrm{~s}$ after ignition, and the temperature at the ignition point are only about $13^{\circ} \mathrm{C}$ higher than that at the monitoring point $50 \mathrm{~m}$ away from the ignition point. After the time exceeds $20 \mathrm{~s}$ after ignition, the temperature at the monitor at the ignition point rises dramatically, reaching $69.7^{\circ} \mathrm{C}, 90.4^{\circ} \mathrm{C}$ and $105.3^{\circ} \mathrm{C}$ at $20 \mathrm{~s}, 40 \mathrm{~s}$ and $60 \mathrm{~s}$ respectively. The monitor issues a fire alarm as early as $20 \mathrm{~s}$, reminding the monitoring department to take fire extinguishing measures promptly. As shown in Figure 7, after the coal mine fire is extinguished, the peak temperature decreases significantly over 


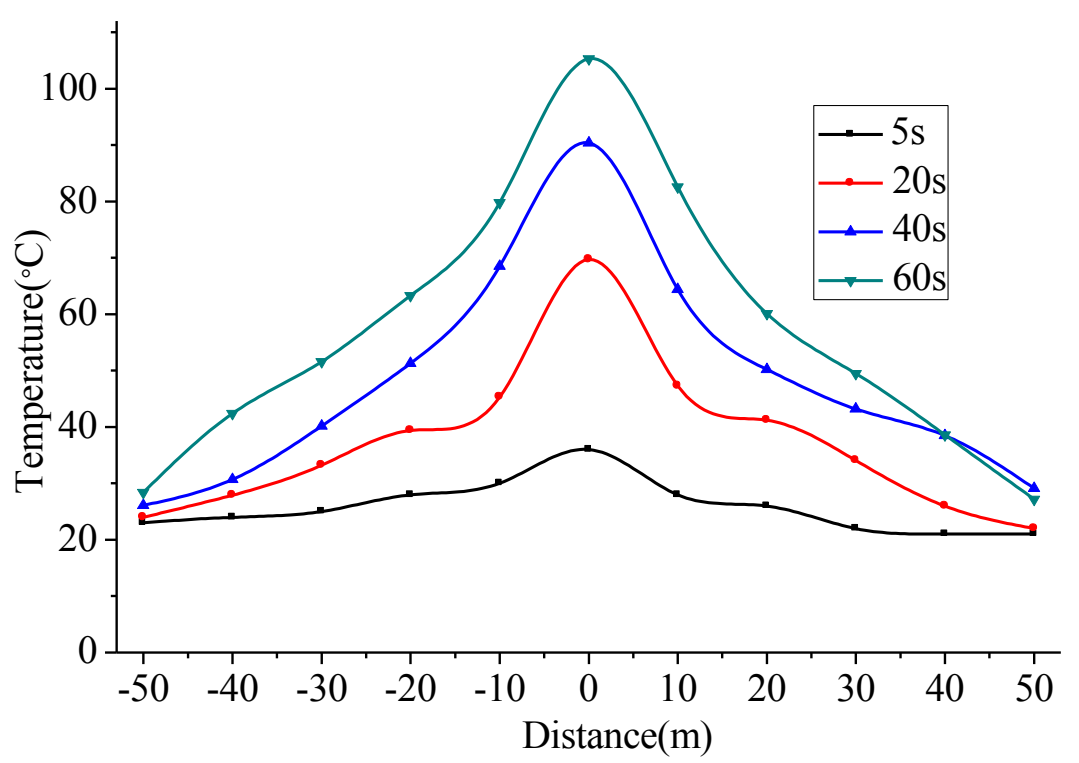

Fig. 6. The temperature variation with distance before the mine is on fire

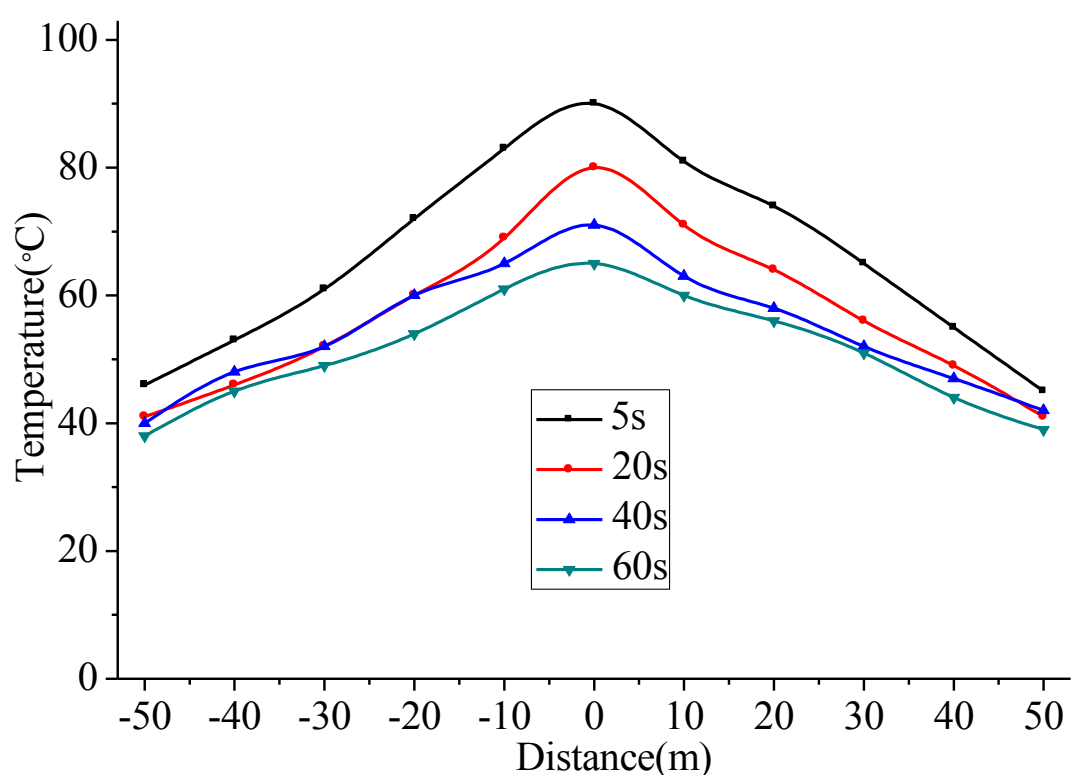

Fig. 7. The temperature variation with distance after the fire is extinguished

time. From $5 \mathrm{~s}$ to $60 \mathrm{~s}$, the peak temperature declines from $90^{\circ} \mathrm{C}$ to $65.6^{\circ} \mathrm{C}$. Due to poor ventilation in the coal mine, the monitoring point with the highest temperature is permeated with thick smoke, resulting in relatively high temperatures at the surrounding monitoring nodes. 


\section{Conclusion}

In view of the potential fire in coal mine production, this paper proposes a coal mine fire monitoring system based on Zig-bee technology, and discusses the network data transmission process in the system. Applied to an actual coal mine, the system achieves a sound fire monitoring effect. The conclusions are as follows:

(1) The proposed WSN coal mine fire monitoring system consists of three subsystems, namely data acquisition subsystem, control center subsystem and emergency response subsystem. With sensor nodes as the basic unit, the WSN consists of five parts: sensor module, treatment module, wireless communication module, location module and power supply module. The system can monitor the air temperature, humidity and smoke concentration of fire in the coal mine, thereby providing effective basis for monitoring department to make decisions on fire prevention and control measures.

(2) It is demonstrated in the on-site monitoring test that, when a fire takes place, the proposed WSN can effectively monitor the trend of fire in the coal mine. Based on temperature variations with spatial distribution after ignition and extinguishment, it is proved that the fire monitoring system is capable of issuing alarm in a timely manner, and illustrates the temperature distribution in details. The proposed system does a better job than other types of fire monitors because it integrates the air temperature, humidity and smoke concentration after the fire broke out into the fire monitoring process.

\section{$5 \quad$ References}

[1] Stracher, G. B. (2004). Coal fires burning around the world: a global catastrophe. International Journal of Coal Geology, 59(s 1-2), 1-6. https://doi.org/10.1016/j.coal.2004.01.001

[2] Stracher, G. B., Taylor, T. P. (2004). Coal fires burning out of control around the world: thermodynamic recipe for environmental catastrophe. International Journal of Coal Geology, 59(1), 7-17. https://doi.org/10.1016/j.coal.2003.03.002

[3] Wang H. Y., Cheng Y. F., Bo Y. (2015). Adsorption effect of overlying strata on carbon dioxide in coalfield fire area, International Journal of Heat and Technology, 33(3), 11-18. https://doi.org/10.18280/ijht.330302

[4] Gupta, R. P., Prakash, A. (1998). Cover: reflectance aureoles associated with thermal anomalies due to subsurface mine fires in the jharia coalfield, india. International Journal of Remote Sensing, 19(14), 2619-2622. https://doi.org/10.1080/014311698214415

[5] Song, Z., Kuenzer, C. (2014). Coal fires in china over the last decade: a comprehensive review. International Journal of Coal Geology, 133, 72-99. https://doi.org/10.1016/j.coal. 2014.09.004

[6] Deng, J., Xiao, Y., Lu, J., Wen, H., Jin, Y. (2015). Application of composite fly ash gel to extinguish outcrop coal fires in china. Natural Hazards, 79(2), 881-898. https://doi.org/10.1007/s11069-015-1881-9

[7] Cao, K., Zhong, X., Wang, D., Shi, G., Wang, Y., Shao, Z. (2012). Prevention and control of coalfield fire technology: a case study in the antaibao open pit mine goaf burning area, china. International Journal of Mining Science and Technology, 22(5), 657-663. https://doi.org/10.1016/j.ijmst.2012.08.011 
[8] Deng, J., Xiao, Y., Li, Q., Lu, J., Wen, H. (2015). Experimental studies of spontaneous combustion and anaerobic cooling of coal. Fuel, 157, 261-269. https://doi.org/10.1016/j.fuel.2015.04.063

[9] Jones, J. C. (1999). Calculation of the frank-kamenetskii critical parameter for a cubic reactant shape from experimental results on bituminous coals. Fuel, 78(1), 89-91. https://doi.org/10.1016/S0016-2361(98)00116-1

[10] Perrone D., Amelio M. (2016). Numerical simulation of MILD (moderate or intense lowoxygen dilution) combustion of coal in a furnace with different coal gun positions, International Journal of Heat and Technology, 34(S2), S242-S248. https://doi.org/10.18280/ ijht.34S208

[11] Zhang H. F., Gao E. X. (2015). 3D numerical simulation and influencing factors of loose top coal spontaneous combustion in roadway, International Journal of Heat and Technology, 33(3), 91 -96. https://doi.org/10.18280/ijht.330313

[12] Yu, Y., \& Zhao, H. (2005). A novel demodulation scheme for fiber bragg grating sensor system. IEEE Photonics Technology Letters, 17(1), 166-168. https://doi.org/10.1109/LPT. 2004.836907

[13] Willett, M. J., Wykes, J. S., Powell, G. A., Gibson, M. J., Cooke, A. (1995). The use of a distributed optical fibre temperature sensing system to monitor underground mine roadways for spontaneous combustion. International Journal of Rock Mechanics \& Mining Sciences \& Geomechanics Abstracts, 33(4), 190.

[14] Zhang, S., Zhang, H. (2012). A review of wireless sensor networks and its applications. IEEE International Conference on Automation \& Logistics, 17(4), 386-389. https://doi.org/10.1109/ical.2012.6308240

[15] Mihajlov, B., \& Bogdanoski, M. (2011). Overview and analysis of the performances of zigbeebased wireless sensor networks. International Journal of Computer Applications, 29(12), 28-35. https://doi.org/10.5120/3704-5138

\section{Authors}

Chengyu Bai is with Xi'an Railway Vocational \& Technical Institute, Traction Power College, Shaanxi 710026, Xi'an, China. His research interests include Electrical Engineering. (Email: bcy_2000@163.com).

Article submitted 09 February 2017. Published as resubmitted by the author 09 March 2017. 